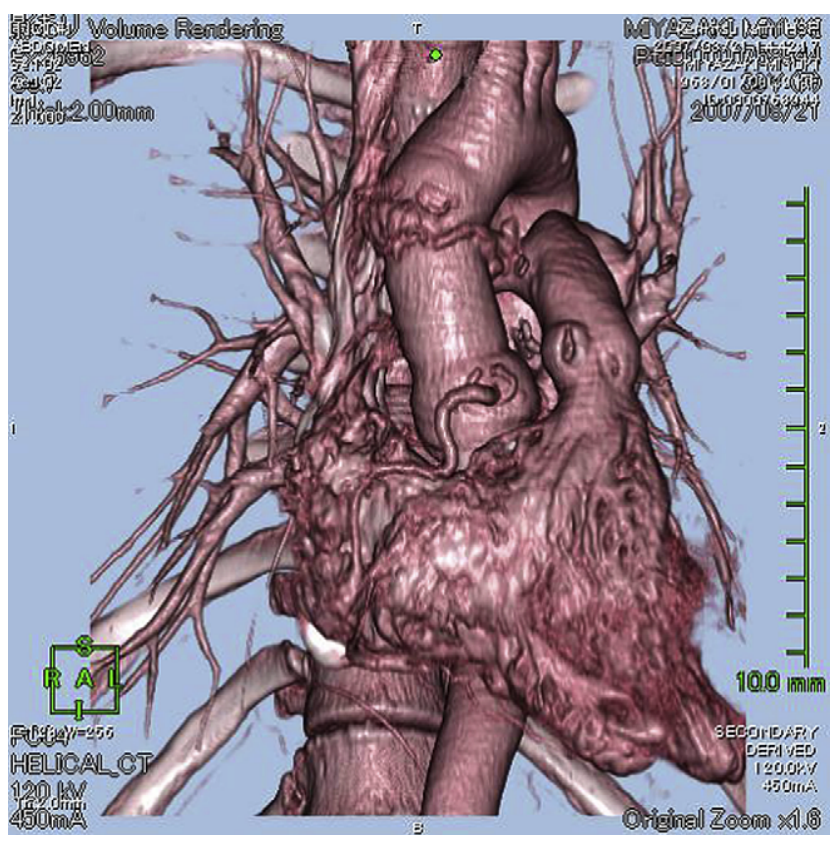

FIGURE 2. Computed tomography after surgery.

was administered $15 \mathrm{mg}$ of steroids immediately post-surgery. She had a good recovery and was discharged 10 days post-surgery.

\section{CONCLUSIONS}

Even when Takayasu arteritis is controlled by steroid therapy, the aorta can be in an active inflammatory phase. Although Amano and colleagues ${ }^{2}$ succeeded in treating 2 out of 8 patients with acute inflammatory Takayasu by applying circumferential Teflon felt to the proximal sutures, using the Carrel patch technique in coronary anastomoses, and topically applying fibrin glue, it is usually too risky to perform surgery in a patient with Takayasu arteritis during acute inflammation because of potential valve and graft detachment. Matsuura and colleagues ${ }^{3}$ reported that 10 of 90 patients in a series had evidence of acute inflammation during operation, and 4 of these 10 patients developed valve and graft detachment. Takayasu arteritis was disguised by a normal CRP, and this case showed that patients with Takayasu arteritis should be treated preoperatively with steroid therapy for at least six months, making sure that the CRP remains negative during that time.

\section{References}

1. Song MH, Tokuda Y, Ueda Y. A novel method of proximal suturing of CarboSeal: aorta folded-over technique. Gen Thorac Cardiovasc Surg. 2007;55:270-1.

2. Amano J, Suzuki A, Tanaka H, Sunamori M. Surgical treatment for annuloaortic ectasia in Takayasu arteritis. Int J Cardiol. 1998;66:S197-202.

3. Matsuura K, Ogino H, Kobayashi J, Ishibashi-Ueda H, Matsuda H, Minatoya K et al. Surgical treatment of aortic regurgitation due to Takayasu arteritis. Circulation. 2005;112:3707-12.

\title{
Partial left pulmonary artery sling associated with multiple ventricular septal defects: A rare congenital anomaly
}

\author{
C. Tissot, MD, J. R. Darst, MD, A. K. Kaza, MD, A. K. Younoszai, MD, and E. da Cruz, MD, Denver, Colo
}

Partial anomalous left pulmonary artery is a rare condition. We present a case of partial left pulmonary artery sling, associated with multiple ventricular septal defects, where the lower posterior branch arises from the right pulmonary artery.

\section{CLINICAL SUMMARY}

A premature male infant of 30 week's gestation was delivered abdominally in an outreach hospital. He was intubated

\footnotetext{
From the Heart Institute, Department of Pediatrics, The Children's Hospital of Denver, University of Colorado at Denver \& Health Sciences Center, Denver, Colo. Received for publication Oct 22, 2007; accepted for publication Dec 14, 2007. Address for reprints: Eduardo da Cruz, MD, Director, Cardiac Intensive Care Unit, Associate Professor of Pediatrics, The Children's Hospital of Denver, University of Colorado at Denver \& Health Sciences Center, 13123 E 16th Ave, Aurora-Denver, CO 80045 (E-mail: dacruz.eduardo@tchden.org).

J Thorac Cardiovasc Surg 2008;136:1085-7

0022-5223/\$34.00

Copyright (c) 2008 by The American Association for Thoracic Surgery doi:10.1016/j.jtcvs.2007.12.054
}

in the delivery room, and surfactant was administered. Clinical examination revealed an imperforate anus, a cleft palate, the presence of two neonatal teeth, and dysmorphic facies. A malformative workup showed a small right pelvic kidney, severe left hydronephrosis, multiple "swiss cheese" ventricular septal defects, and a patent ductus arteriosus with bidirectional shunting. Neonatal hypothyroidism was also diagnosed. The neonate underwent a colostomy soon after birth and was extubated on the fourth day after birth. His clinical evolution during the first weeks of life showed progressive increased work of breathing with clinical signs of heart failure, motivating his transfer to our center.

Echocardiography performed on admission at 6 weeks after birth demonstrated the multiple ventricular septal defects with low velocity left-to-right shunt. Short-axis views of the heart demonstrated a main pulmonary artery branching normally anterior to the trachea into right and left pulmonary 


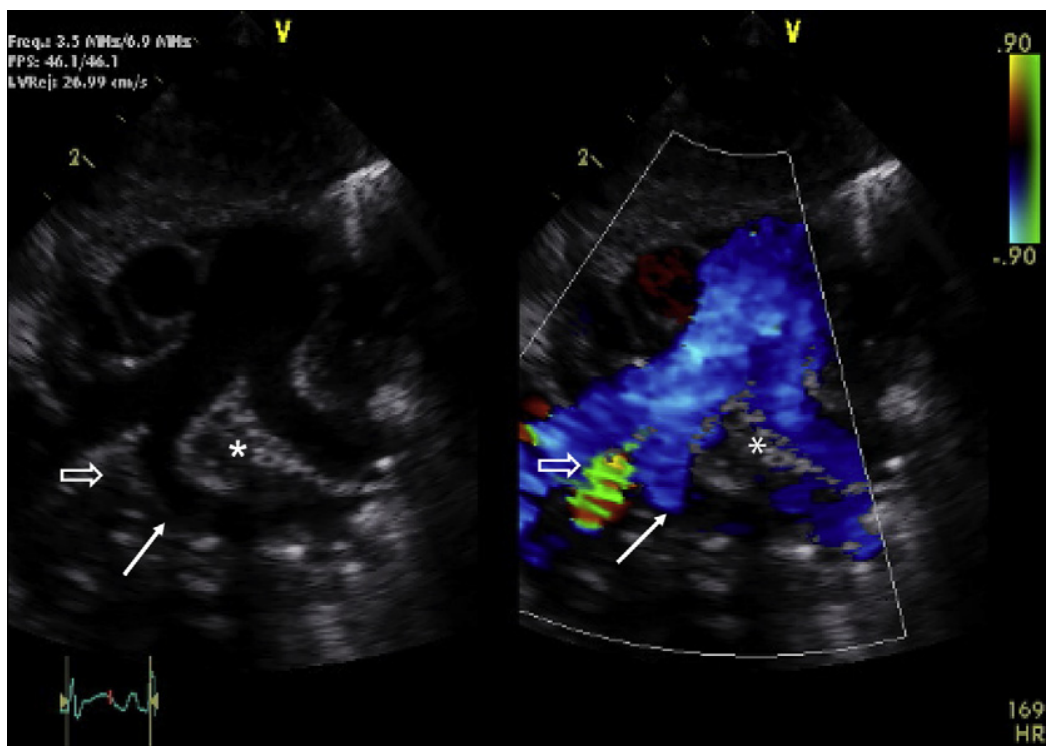

FIGURE 1. Left pulmonary angiogram. Tip of angiographic catheter lies in left pulmonary artery, which opacifies first, followed by pulmonary trunk and right pulmonary artery. Right pulmonary artery gives rise to proximal branch that itself divides into anomalous left pulmonary artery (arrow), coursing leftward and posterior and vascularizing left lower posterior segment, and another branch, vascularizing right lower lobe. This right lower lobe branch shows significant proximal narrowing (open arrow).

arteries. The right pulmonary artery bifurcated again, however, giving rise to an unusual vessel coursing leftward and posterior to the trachea (Figure 1), suggestive of a partial left pulmonary artery sling. A thoracic computed tomographic scan confirmed this diagnosis, with the anomalous left lower posterior branch of the left pulmonary artery aris-

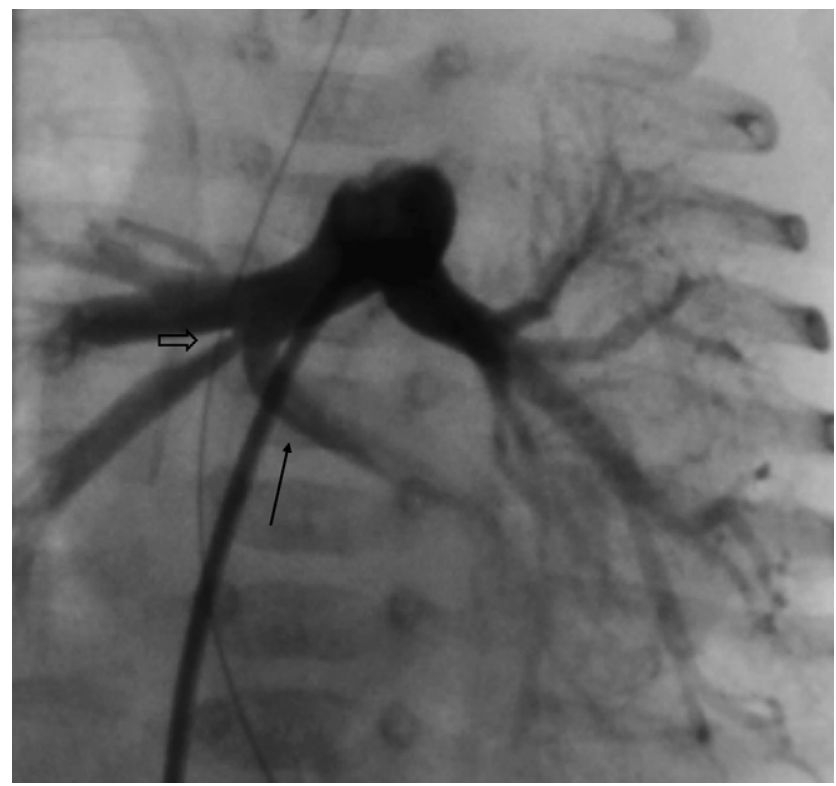

FIGURE 2. Echocardiographic short-axis view. Main pulmonary artery branches into left and right pulmonary arteries. Anomalous left pulmonary artery (arrow) arises from proximal right pulmonary artery, posterior to trachea (asterisk). Significant narrowing of right lower lobe branch is noted (open arrow) with continuous flow by color Doppler imaging. ing posterior to the trachea. No airway obstruction was seen. Cardiac catheterization confirmed the diagnosis of partial left pulmonary artery sling, with the anomalous left lower lobe pulmonary branch arising from the proximal right pulmonary artery, posterior to the airways, vascularizing a left lower posterior pulmonary segment (Figure 2). An anomalous right lower lobe branch was also seen just distal to the anomalous left lower branch, with significant proximal narrowing. The right pulmonary artery then divided into right upper, middle, and lower lobe branches in the usual positions. The left pulmonary artery divided into left upper lobar, lingular, and lower anterior segmental branches. The infant underwent pulmonary arterial banding. Because of the absence of airway compression, nothing was done about the abnormal left and right pulmonary arterial branches.

\section{DISCUSSION}

Partial anomalous left pulmonary artery is a rare condition. It is defined as the coexistence of a normal left pulmonary artery and an anomalous component arising from the right pulmonary artery, usually providing blood flow to the left lower lobe. Two forms have been documented. The first, in which the anomalous component arises anterior to the trachea from the proximal right pulmonary artery, is called partial anomalous left pulmonary artery; in the second form, known as partial left pulmonary artery sling, the anomalous component arises posterior to the airway. The latter can result in compression of the distal trachea and adjacent right bronchus, which surprisingly was not the case in our patient.

Embryologically, the pulmonary arteries are thought to be part of the arterial buds arising from the ventral sixth 
aortic arch that surrounds the lung bud. It has been proposed that pulmonary artery sling arises when the left lung bud fails to connect with the left sixth arch and instead forms an anastomosis with the right sixth arch. If this occurs dorsal to the developing lung bud, it results in a left pulmonary artery arising from the right pulmonary artery, coursing posterior to the trachea, creating the sling. The same explanation may apply to the partial left pulmonary artery sling, in which the anomalous component courses behind the trachea because of a dorsal connection to the lung bud. If such a connection occurs ventral to the developing lung bud, this result in a partial anomalous left pulmonary artery. ${ }^{1}$

Anomalous left pulmonary artery is associated with other congenital heart defects in $40 \%$ to $50 \%$ of cases. Partial anomalous left pulmonary artery and partial left pulmonary artery sling have been described in association with ventricular septal defect, ${ }^{1}$ double-outlet right ventricle with unbalanced atrioventricular septal defect, ${ }^{2}$ coarctation of the aorta, ${ }^{2,3}$ and mitral stenosis. ${ }^{2,3}$ To our knowledge, associa- tion with "swiss cheese" ventricular septal defects has not previously been reported. Interestingly, Koch and colleagues $^{3}$ reported a case of partial anomalous left pulmonary artery in association with imperforate anus, as in our patient, suggesting an association with a more complex process of dysmorphogenesis and a genetic background. This is reinforced by the association of other congenital anomalies present in our patient. The fact that our patient did not have an obstructive airway is unusual in the setting of a partial left pulmonary artery sling, which encircles the lower trachea. The patient was discharged in good condition but will require careful follow-up of the pulmonary vasculature and central airways.

\section{References}

1. Erickson LC, Cocalis MW, George L. Partial anomalous left pulmonary artery: new evidence on the development of the pulmonary artery sling. Pediatr Cardiol. 1996; 17:319-21.

2. Fountain-Dommer RR, Shirali GS, Wiles HB, Larsen RL. Noninvasive diagnosis of partial anomalous left pulmonary artery. J Am Soc Echocardiogr. 2001;14:745-6.

3. Koch A, Hofbeck M, Gerling S, Buheitel G, Singer H. [Partial anomalous origin of the left pulmonary artery]. [German] Z Kardiol. 2000;89:118-21.

\title{
Cardiac tamponade secondary to traumatic intrapericardial diaphragmatic hernia
}

\author{
Affes Nejmeddine, MD, ${ }^{\mathrm{a}}$ Abdenader Mohamed, MD, ${ }^{\mathrm{b}}$ Khemakem Khalil, MD, ${ }^{\mathrm{c}}$ Ben Salah Khalil, MD, ${ }^{\mathrm{a}}$ and \\ Beyrouti Mohamed Issam, MD, ${ }^{a}$ Sfax, Tunisia
}

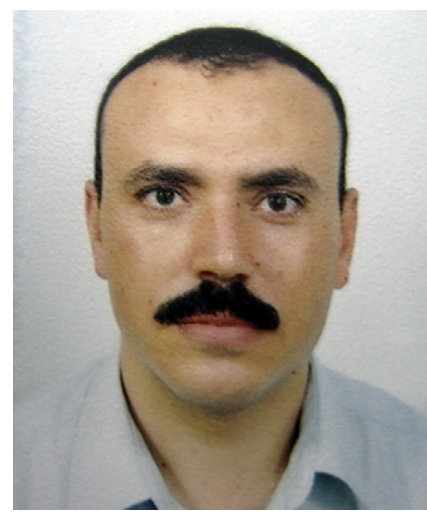

Dr Nejmeddine.

\footnotetext{
From the Departments of General Surgery, ${ }^{\mathrm{a}}$ Cardiac Surgery, ${ }^{\mathrm{b}}$ and Anesthesia, ${ }^{\mathrm{c}}$ Habib Bourguiba Hospital, Sfax, Tunisia.

Received for publication Oct 25, 2007; accepted for publication Dec 9, 2007.

Address for reprints: Affes Nejmeddine, MD (E-mail: affesnejm@yahoo.fr).

J Thorac Cardiovasc Surg 2008;136:1087-9

$0022-5223 / \$ 34.00$

Copyright (c) 2008 by The American Association for Thoracic Surgery

doi:10.1016/j.jtcvs.2007.12.075
}

An unusual case of cardiac tamponade secondary to traumatic intrapericardial diaphragmatic hernia is presented: a defect of the pericardium, with herniation of the stomach and the greater omentum into the pericardial sac. A preoperative diagnosis was suspected by clinical and chest x-ray signs and confirmed by computed tomography (CT). A laparotomy was quickly performed. Successful operative repair of the tear was performed with interrupted reabsorbable sutures. The case is discussed, and the management of patients with these rare lesions is reviewed.

Intrapericardial diaphragmatic hernia results from a posttraumatic and severe compressive injury of the chest and abdomen. Herniation into the pericardium is rare; approximately 1 posttraumatic intrapericardial hernia is reported every year. We review the posttraumatic intrapericardial diaphragmatic hernia cases in the literature to discuss the diagnostics and management of this lesion.

\section{CLINICAL SUMMARY}

A 56-year-old man was involved in a car crash that caused a bilateral costal fracture with blunt abdominal trauma. The 